\title{
ESTUDO DA VARIABILIDADE DIURNA DA PRECIPITAÇÃO REGIÃO SUL DO BRASIL
}

\author{
Caio Guerra ${ }^{1}$ and Mario Quadros ${ }^{1}$
}

\begin{abstract}
O clima na Região Sul do Brasil tem forte influência de sua posição geográfica, uma região de transição entre os trópicos e as latitudes médias, possuindo características de ambas em sua grande extensão latitudinal. Este fator, combinado a complexidade do terreno e os efeitos da continentalidade, resultam em diferentes modos climáticos e de tempo nestas áreas, sendo observados grandes contrastes térmicos e diferentes regimes pluviométricos ao longo do ano. As particularidades destes diferentes modos climáticos ainda carecem de estudos e maior detalhamento, sendo o objetivo principal deste trabalho avançar na discussão do tema. Para tal, foram utilizados dados horários de 95 (noventa e cinco) estações meteorológicas automáticas do Instituto Nacional de Meteorologia (INMET) na Região Sul, com séries temporais variáveis de cinco a vinte anos, para calcular a média horária e avaliar seu comportamento nas diferentes regiões dos estados. Para analisar de forma espacial também utilizou-se de métodos de interpolação por Krigagem. A análise das estações e dos mapas horários indicaram um padrão bem definido de precipitação. Os menores valores de acumulados são observados entre meia noite e 5 (cinco) horas da manhã. A partir do amanhecer, começa a ganhar força no oeste dos três estados, com destaque para o sudoeste do Paraná, Oeste Catarinense e Noroeste do Rio Grande do Sul, e atinge seu máximo entre meio dia e 3 (três) horas da tarde. Em meados da tarde, nota-se o deslocamento do máximo de precipitação do oeste para o litoral, que atinge seu máximo entre final da tarde e noite, especialmente entre Santa Catarina e Paraná, perdendo força apenas na madrugada.
\end{abstract}

\section{Keywords}

mesoclima, tratamento de dados, interpolação

\section{INTRODUÇÃO}

A Região Sul do Brasil é caracterizada pela transição entre os trópicos e as latitudes médias, relevo diversificado e extensa continentalidade. Estes aspectos resultam na heterogeneidade climática da região, com diferentes regimes de precipitação e grande contraste térmico.

O conhecimento regionalizado do tempo e clima é de extrema importância para diversos setores da sociedade e pode trazer benefícios para a gestão de desastres naturais. $\mathrm{O}$ entendimento da suscetibilidade em relação ao clima das variadas regiões do estado proporciona maior clareza nas demandas e, consequentemente, nos recursos necessários para as mesmas. Apesar de existirem diversos estudos climáticos da região, há grande oportunidade de aprofundamento nos conhecimentos de forma mais regionalizada, nos diferentes mesoclimas da região, a partir do tratamento mais rigoroso dos dados já disponibilizados.

O objetivo principal deste trabalho é realizar uma regionalização do clima no Sul do Brasil, a partir do melhor entendimento da influência dos sistemas meteorológicos e os fatores climáticos de forma localizada. Para tal, pretendese realizar aperfeiçoar a análise da série temporal da rede de estações meteorológicas disponíveis a partir de métodos estatísticos e análise objetiva, assim como entender como as variáveis meteorológicas respondem aos sistemas sinóticos e efeitos topográficos de forma regionalizada, investigando circulações de mesoescala e sua relação com extremos de precipitação em regiões de relevo complexo. Especificamente, o trabalho propõe:

- Determinar, a partir de dados de estações meteorológicas automáticas (EMAs) e de produtos de precipitação, a variabilidade espacial e temporal dos elementos meteorológicos precipitação, temperatura, vento e umidade relativa;

- Avaliar os resultados obtidos com as normais climatológicas do Instituto Nacional de Meteorologia (INMET)

- Identificar possíveis efeitos de menor escala temporal, como análise do ciclo diurno e o comportamento de brisa.

- Avaliar diferentes métodos de agrupamento, como o de Grimm, Ferraz, Simone, and Gomes (1998), Severo (2008) e Reboita and Simões (2010), com o objetivo de identificar regiões que apresentam padrões similares, possibilitando uma caracterização do clima de forma regionalizada.

- Relacionar os principais sistemas meteorológicos de escala sinótica e mesoescala responsáveis pelos padrões climatológicos regionalizados.

\footnotetext{
${ }^{1}$ Instituto Federal de Santa Catarina, Florianópolis, Santa Catarina Email: mquadro@ifsc.edu.br (Mario Quadros)

Corresponding author:

Caio Guerra, Instituto Federal de Santa Catarina, Florianópolis, Santa Catarina

Email: caio.go@aluno.ifsc.edu.br
} 


\section{REVISÃO BIBLIOGRÁFICA}

O regime de chuva no sul do Brasil é atribuído a uma série de sistemas meteorológicos, sendo a precipitação bem distribuída ao longo do ano, especialmente nas áreas mais ao sul, com variações no volume e também na qualidade da chuva entre os meses de verão e inverno (Reboita \& Simões, 2010). Dentre os sistemas, cita-se a atuação e formação dos ciclones em baixos e médios níveis, frentes frias, SCMs, bloqueios atmosféricos e efeitos de circulações locais, como a brisa marítima, entre outros.

Destaca-se a importância dos bloqueios atmosféricos em eventos de seca, visto que o sistema atua de forma a impedir que os sistemas frontais avancem para as áreas mais centrais do país. A análise de Rodrigues, Guimarães, Franco, and Sugahara (2004) et al verificou que, com uma frequência baixa, existem intervalos de 25 a 32 dias sem passagem de frentes frias no litoral de Santa Catarina, bem maiores do que a média de 3 a 8 dias. Os autores argumentam que estes eventos podem estar associados à formação de bloqueios.

Quanto às temperaturas, a sazonalidade tem um papel marcante, apresentando um contraste térmico expressivo entre o verão e o inverno. Também destaca-se as áreas elevadas, nos planaltos e serras, especialmente entre o Rio Grande do Sul e Santa Catarina, que garantem um forte gradiente espacial de temperatura em relação às regiões mais baixas.

É importante lembrar que as condições climáticas podem sofrer modificações quando há atuação do Fenômeno El Niño-Oscilação Sul (ENOS), devido ao transporte anômalo de calor e umidade do Oceano Pacífico para a atmosfera. Segundo Grimm and Tedeschi (2009), tanto na fase positiva (El Niño) quanto na negativa (La Niña) se observa uma influência na frequência dos extremos de precipitação na América do Sul. De forma simplificada para a Região Sul do Brasil, se observa um aumento na precipitação em anos de El Niño e uma diminuição em anos de La Niña, principalmente nos meses de inverno.

Apesar dos autores abordarem as principais características climáticas da região, ainda carece de estudos regionalizados para aprofundar o conhecimento científico dos sistemas responsáveis pelos padrões climáticos de cada mesorregião. Como exemplo, Grimm et al. (1998), ao analisar a distribuição anual da precipitação na Região Sul do país, encontraram diferentes picos da estação úmida, o que indica a atuação de diferentes regimes climáticos de precipitação nestas áreas. A partir disso, foram descritas quatro modos climáticos de precipitação: (i) no centro-leste, com pico de precipitação no verão austral, modo similar a subtropical com características de monção; (ii) uma região de transição entre Santa Catarina e Rio Grande do Sul, com máximo de precipitação entre as estações de verão e outono, marcando um clima de transição; (iii) pequenas faixas nas regiões de divisa destes estados com máximos de precipitação no inverno, típico de um regime de latitudes médias, com eventos precipitantes associados a atuação de ciclones extratropicais e, (iv) um pico de precipitação entre os meses de janeiro e março nas faixas litorâneas, com limite desenhado nas barreiras orográficas próximas à costa, indicando uma possível participação da topografia no regime de precipitação local.

\section{METODOLOGIA}

Para o desenvolvimento do trabalho, são utilizados os dados das estações meteorológicas das redes automáticas do Instituto Nacional de Meteorologia (INMET). O tratamento da série de dados é feito através de técnicas estatísticas a partir da utilização de programas computacionais nas linguagens python e R.

Em uma primeira etapa do estudo serão geradas composições espaciais anual, sazonal e mensal, a partir do método de krigagem descrito por Oliver and Webster (1990), das variáveis meteorológicas temperatura $\left({ }^{\circ} \mathrm{C}\right)$ e umidade relativa (\%) mínima, média e máxima a 2 m, direção (graus) e velocidade do vento $(\mathrm{m} / \mathrm{s})$ a $10 \mathrm{~m}$, pressão reduzida ao nível médio do mar $(\mathrm{hPa})$ e precipitação acumulada $(\mathrm{mm})$.

$\mathrm{Na}$ segunda etapa da metodologia, os mapas de temperatura média e precipitação acumulada serão comparados com as normais climatológicas de 1961-1990 e 1991-2010 do INMET. Com esta comparação, objetiva-se avaliar o comportamento do padrão climatológico das diversas mesorregiões, visando identificar efeitos de menor escala temporal. Este projeto também propõe a análise do ciclo diurno, a partir da evolução horária das variáveis temperatura, umidade relativa e precipitação acumulada. Sobre as regiões litorâneas e de vales, a análise do ciclo diurno do vento possibilitará o estudo do comportamento das brisas marítima/terrestre e de vale/montanha.

$\mathrm{Na}$ etapa final do projeto, para expandir a discussão dos trabalhos prévios, pretende-se utilizar métodos de agrupamento de variáveis meteorológicas Grimm et al. (1998); SEVERO (2008); REBOITA, 2010), como umidade e vento, que possuem um papel importante na caracterização do clima das regiões, sendo diretamente afetado pelos efeitos da continentalidade e orografia. Assim, tem-se o objetivo de melhor caracterizar os modos climáticos atuantes nas mesorregiões do Estado, assim como identificar possíveis padrões não discutidos anteriormente, que não são factíveis de discussão com a utilização apenas do regime térmico e pluviométrico. Ressalta-se que, neste trabalho, são apresentados os resultados preliminares obtidos para a variável precipitação acumulada.

Com os resultados obtidos, este projeto propõe estabelecer relações dos composites obtidos com os principais sistemas meteorológicos de escala sinótica e mesoescala responsáveis pelos climatológicos regionalizados no Sul do Brasil.

\section{RESULTADOS E DISCUSSÃO}

Como descrito na metodologia, em primeira análise, apenas a variável de precipitação acumulada $(\mathrm{mm})$ foi investigada, buscando o comportamento desta em diferentes regiões do estado de Santa Catarina, tanto sua característica sazonal com o total acumulado mensal, quanto sua variação diurna média a partir dos dados horários. Para analisar de forma pontual, foram selecionadas quatro estações meteorológicas do INMET, sendo estas Florianópolis, Bom Jardim da Serra (Morro da Igreja), Caçador e São Miguel do Oeste, representando regiões geográficas distintas. Em Florianópolis os dados compreendem o período de 2003 a 2020, Bom Jardim da Serra de 2007 a 2020 e as demais estações de 2008 a 2020. Destas estações destacamse algumas características importantes. Florianópolis se 
posiciona no litoral catarinense, influenciado diretamente pelo oceano e os sistemas frontais de forma mais frequente. Bom Jardim da Serra se localiza no Planalto Sul e tem como característica determinante sua altitude. Caçador fica no Meio Oeste, região central do estado, com menor influência do oceano em relação às estações prévias. Já São Miguel do Oeste, localizada no Extremo Oeste, observa efeitos diretos da continentalidade. Na Figura 1 são apresentados os acumulados médios horários de precipitação. De maneira geral, em Florianópolis e Bom Jardim da Serra os acumulados são maiores entre meados da tarde e madrugada, enquanto em Caçador e São Miguel do Oeste os acumulados são maiores entre o início da tarde e noite.

Para verificar se o padrão de chuva observado nas estações é verificado de forma espacial, isto é, se existem diferentes horários que a chuva é favorecida em cada região, foi feita uma análise espacial do ciclo diurno médio da precipitação, a partir do método de Krigagem, para interpolação das 95 estações do INMET localizadas na Região Sul do Brasil.

Os mapas de média horária de precipitação, apresentados na figura 2, ao serem analisados de forma qualitativa, complementam o observado anteriormente.

Os menores valores são indicados nas cores mais claras e os maiores nas cores escuras, variando entre 0,15 e 0,40 $\mathrm{mm} / \mathrm{h}$.

Os menores valores de acumulados são observados entre meia noite e 5 (cinco) horas da manhã. A partir do amanhecer, começa a ganhar força no oeste dos três estados, com destaque para o sudoeste do Paraná, Oeste Catarinense e Noroeste do Rio Grande do Sul, e atinge seu máximo entre meio dia e 3 (três) horas da tarde. Em meados da tarde, notase o deslocamento do máximo de precipitação do oeste para o litoral, que atinge seu máximo entre final da tarde e noite, especialmente entre Santa Catarina e Paraná, perdendo força apenas na madrugada.

\section{CONCLUSÕES}

A análise das estações e dos mapas horários de precipitação acumulada indicaram diferentes padrões no ciclo diurno entre as distintas regiões do Sul do Brasil, destacando um pico da precipitação no início da tarde no oeste dos estados, com deslocamento para a região litorânea entre o final da tarde e noite. O mínimo ocorre no período da madrugada, com baixos valores médios de precipitação.

Pretende-se ampliar essa discussão utilizando o maior banco de dados disponível atualmente, assim como a partir da inclusão de outras variáveis meteorológicas, que possibilita compor uma descrição mais detalhada do clima de forma regionalizada, discutindo também as influências da sazonalidade de forma regionalizada.

Por fim, deve-se aplicar diferentes métodos de agrupamento para identificar as áreas que apresentam modos climáticos similares no Sul do Brasil e comparar com os resultados obtidos em trabalhos prévios. $\mathrm{O}$ produto final esperado é a produção de um Atlas Climático Regionalizado especificamente para o estado de Santa Catarina. O produto será de fácil consumo para áreas correlatas e população em geral, com função de disseminação de informação. Existe uma demanda para informações climáticas, porém este tipo de informação se apresenta de forma acadêmica ou restrita em atividades operacionais.

\section{Referências}

Grimm, A. M. ., Ferraz, Simone, E., \& Gomes, J. (1998). Precipitation anomalies in southern Brazil associated with El Niño and La Niña events. Journal of climate(11), 2863-2880.

Grimm, A. M. ., \& Tedeschi, R. G. (2009). ENSO and extreme rainfall events in South America. Journal of Climate(7), 1589-1609.

Oliver, M. A. ., \& Webster, R. (1990). Kriging: a method of interpolation for geographical information systems. International Journal of Geographical Information System, 313-332.

Reboita, M., \& Simões. (2010).

Rodrigues, M. L., Guimarães, ., Franco, D. ., \& Sugahara, S. (2004)

Severo, D., \& Luís. (2007). Padrões de circulação anômala associados a episódios úmidos e secos no sul do brasil. inpe. São José dos Campos, SP. 


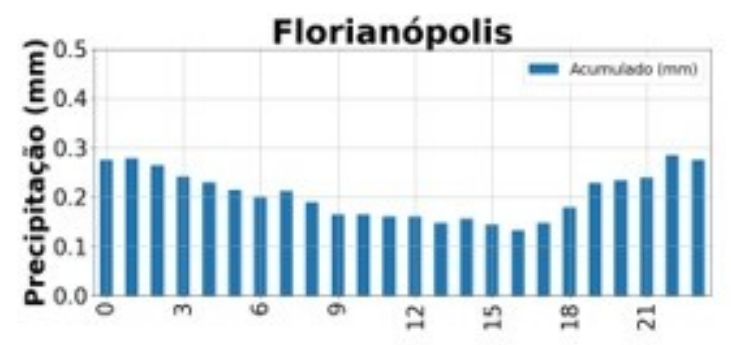

(a)

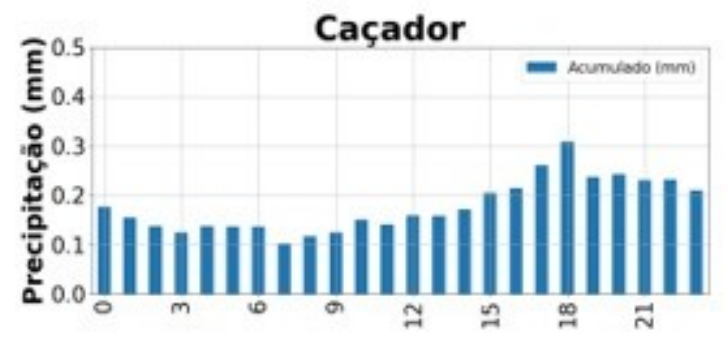

(c)

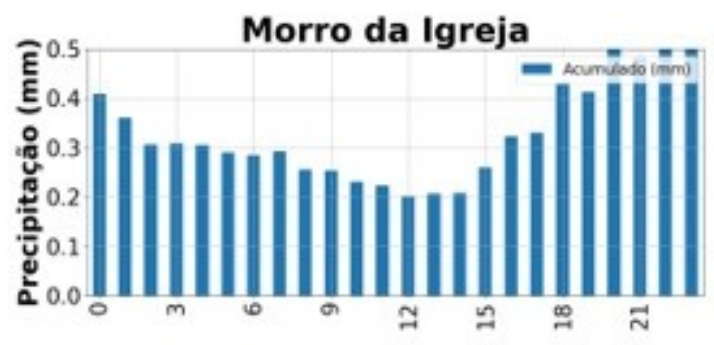

(b)

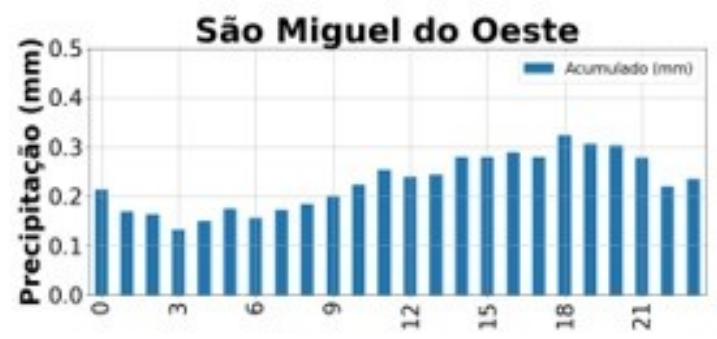

(d)

Figure 1. Média horária dos acumulados de precipitação nasestações de (a) Florianópolis, (b) Bom Jardim da Serra, (c) Caçador e (d) SãoMiguel do Oeste. 


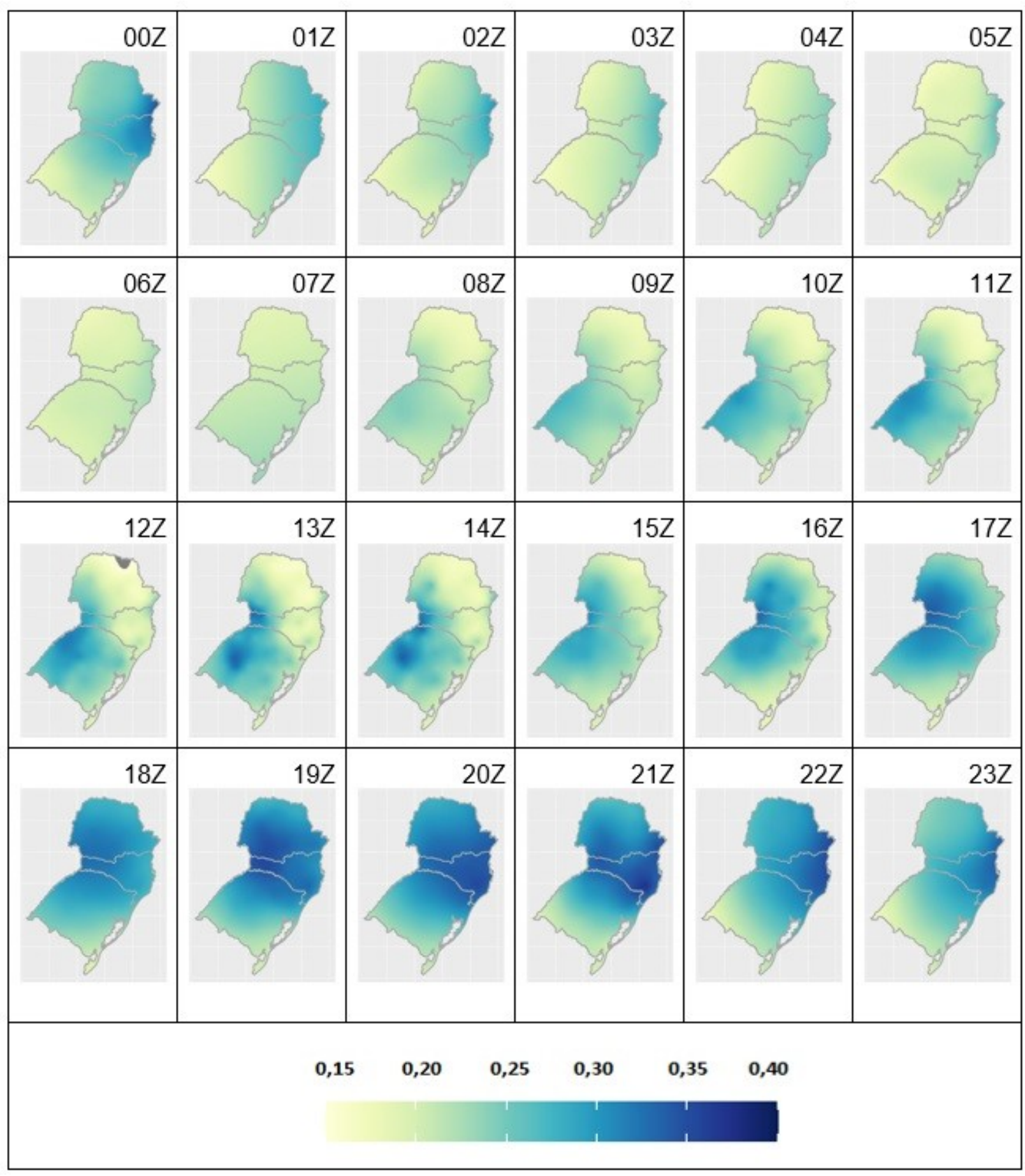

Figure 2. Média dos acumulados de precipitação na Região Sul do Brasil nos respectivos horários, conforme legenda dos mapas, de $00 Z$ a $23 Z$. 